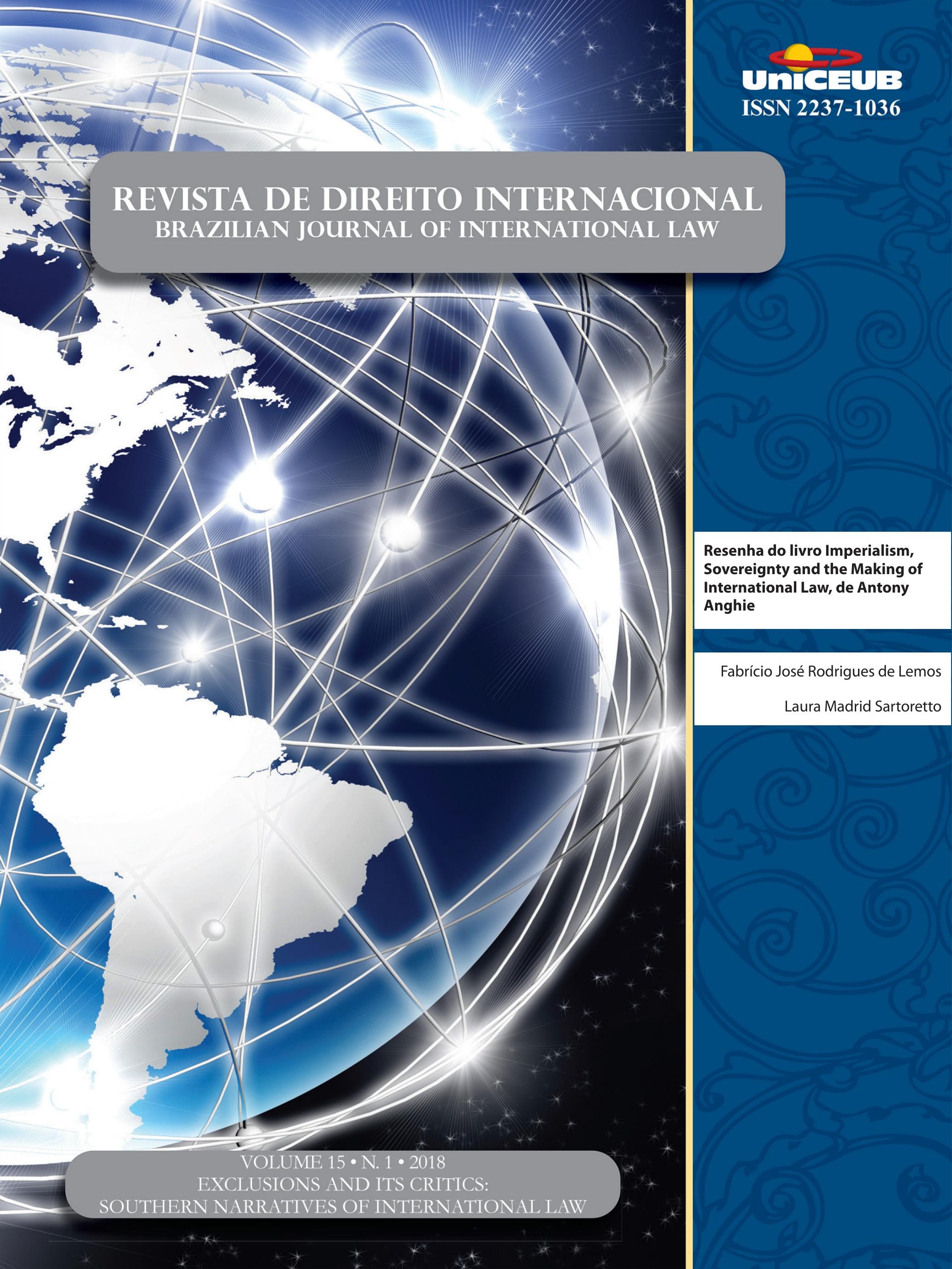




\section{Sumário}

I. Dossiê Especial: Exclusions and its Critics: Southern Narratives of

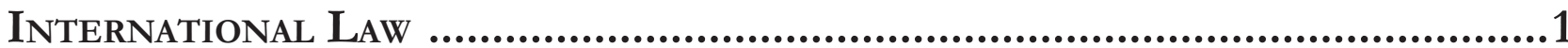

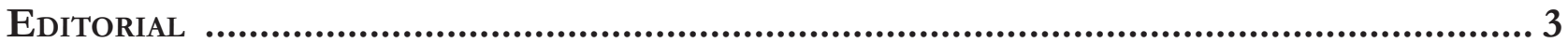

Conseguimos pensar em narrativas críticas do Direito Internacional no Sul Global? ......................... 3

ENTRE A APOLOGIA E A UTOPIA: A POLÍTICA Do DIREITO INTERNACIONAL................................ 6 Martti Koskenniemi e Tradutor João Roriz

A POLÍTICA Do DIREITO INTERNACIONAL: 20 ANOS DEPOIS ...................................................31 Martti Koskenniemi e Tradutor João Roriz

Abordagens terceiro-mundistas para o Direito Internacional: Um Manifesto............42 Bhupinder S. Chimni

Around the pyramid: Political-theoretical challenges to law in the age of global GOVERNANCE

Salem Hikmat Nasser e José Garcez Ghirardi

VOICE AND EXIT: HOW EMERGING POWERS ARE PROMOTING INSTITUTIONAL CHANGES IN THE INTERNATIONAL MONETARY SYSTEM

Camila Villard Duran

LA LIBRE AUTODETERMINACIÓN DE LOS PUEBLOS EN EL SIGLO XXI: UNA APROXIMACIÓN DE LA HISTORIA DEL COLONIALISMO Y EL NEO-COLONIALISMO DESDE LOS PUEBLOS DEL TERCER MUNDO

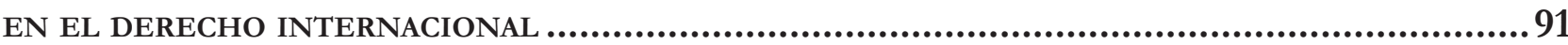

Germán Medardo Sandoval Trigo

INTERNATIONAL CLIMATE CHANGE REGIME AS A PROMOTER OF COLONIAL SYSTEMIC AND SYMBOLIC VIOLENCE: ITS RELATIONSHIP WITH INTERNATIONAL ENVIRONMENT SECURITY AND FOOD SYSTEM THRU THE LENS OF FEMINIST APPROACH 106

Douglas Castro e Bruno Pegorari 
Jus COGENS: AN EUROPEAN CONCEPT? AN EMANCIPATORY CONCEPTUAL REVIEW FROM THE INTER-AMERICAN SYSTEM OF HUMAN RIGHTS

Tatiana de A. F. R. Cardoso Squeff e Marina de Almeida Rosa

O CONHECIMENTO TRADICIONAL RELACIONADO AO COMPLEXO DO CURARE E A LEGISLAÇÃO IN-

TERNACIONAL SOBRE PROPRIEDADE INTELECTUAL. 139

Marcos Vinício Chein Feres e João Vitor de Freitas Moreira

II. Artigos sobre outros temas

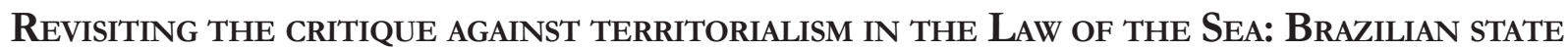
PRACTICE IN LIGHT OF THE CONCEPTS OF CREEPING JURISDICTION AND SPOLIATIVE JURISDICTION ..161 Victor Alencar Mayer Feitosa Ventura

EDUCAÇÃO SUPERIOR INTERCULTURAL, RECONHECIMENTO E REDISTRIBUIÇÃO: O DURO CAMINHO DOS POVOS INDÍGENAS NO EQUADOR 180

Vanessa Wendhausen Cavallazzi, Patrícia Perrone Campos Mello e Raony Soares

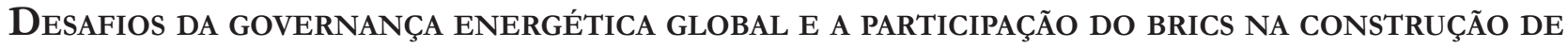
UM NOVO PARADIGMA ENERGÉTICO 200

Fernanda Volpon e Marilda Rosado de Sá Ribeiro

A hermeneutical analysis on the recognition of China as a market economy after 2016.

Alberto Amaral Júnior e Aline Pereira de Carvalho Heringer

THE ISIS ERADICATION OF CHRISTIANS AND YAZIDIS: HUMAN TRAFFICKING, GENOCIDE, AND THE MISSING INTERNATIONAL EFFORTS TO STOP IT

Sarah Myers Raben

The strategic prudence of The Inter-American Court of Human Rights: Rejection OF REQUESTS FOR AN ADVISORY OPINION 255

Cecilia M. Bailliet

Direito Internacional Monocromático: PREVISÃo e apliCaÇÃo dos Direitos LGBTI NA ORDEM INTERNACIONAL 278

Rafael Carrano Lelis e Gabriel Coutinho Galil 
III. RESENHAS

Resenha do livro Empire de Michael Hardt e Antonio Negri 301 Arthur Roberto Capella Giannattasio

Resenha do livro Imperialism, Sovereignty and the Making of International LaW, de

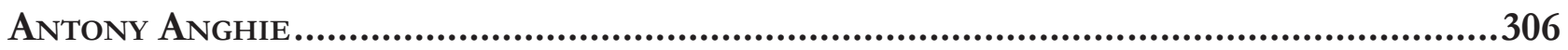

Fabrício José Rodrigues de Lemos e Laura Madrid Sartoretto 


\title{
Resenha do livro Imperialism, Sovereignty and the Making of International Law, de Antony Anghie*
}

\author{
Fabrício José Rodrigues de Lemos**
}

Laura Madrid Sartoretto***

O livro de Antony Anghie, Imperialismo, soberania e a construção do Direito Internacional, aborda a recorrente questão levantada pelos acadêmicos da escola crítica do direito internacional relativa à europeização desse campo do direito. Anghie, em sua obra, vai mais além e inova ao sustentar que, em verdade, o direito internacional é produto do encontro do colonizador com os povos colonizados. Fundamentado e instrumentalizado por valores, cultura, princípios ocidentais, o direito internacional foi desenhado e utilizado para justificar e manter relações de dependência entre o mundo ocidental e o não ocidental. A justificativa axiológica esteve baseada na construção da dinâmica da diferença, que pressupunha um ocidente culto, racional e civilizado, enquanto o resto do mundo era visto como irracional e primitivo. Partindo desse pressuposto, o autor convida os leitores a considerarem os limites, pressuposições e injustiças produzidas e justificadas pelo campo do direito internacional no passado e na atualidade.

A obra de Anghie inicia sua análise no século XVI, passando do naturalismo jurídico ao positivismo, no século XIX, baseado numa distinção entre civilizados e incivilizados, que reproduziu relações históricas de dominação entre os europeus e os povos colonizados, culminando, no século XX, no pragmatismo judicial, fase em as Organizações Internacionais, novos sujeitos de direito internacional, emergem e passam a exercer o papel de reguladores e criadores de normas de boa governança no plano internacional.

No primeiro capítulo da obra, o autor visa compreender a relação entre direito internacional e colonialismo. Para tanto, inicia pela apresentação das ideias de Francisco de Vitoria, teólogo espanhol do século XVI, apontado como um dos primeiros doutrinadores de direito internacional. Apesar de sua importância para a discussão teórica mais em voga à época — qual seja, a (ir)racionalidade dos indígenas do Novo Mundo, embate no qual advogava em favor dos povos ameríndios - Vitoria serviu sobremaneira, consoante aponta Anghie, como um grande teórico do avanço dos interesses colonialistas espanhóis na América. Anghie argumenta que Vitoria, enfocando a questão da soberania, tolhido por uma visão eurocêntrica das diferenças culturais e da própria identidade dos indígenas americanos, a qual veio a marcar, profundamente, sua doutrina, não via a relação Espanha-América como um problema de criação de ordem ou de regulação de embates entre duas sociedades soberanas. Assim, Anghie aponta que Vitoria, adotando um discurso aparentemente neutro - como se dissociado da questão de fundo - teorizou acerca das requisitos da guerra justa, e do problema de dirimir eventuais disputas entre sociedades culturalmente diferentes no plano internacional: ao concluir, Vitoria, por intermédio de uma série de manobras argumentativas, que as práticas espanholas — apresentadas de forma idealizada — deveriam ser universalmente obrigatórias e que os ameríndios não possuíam soberania sobre seu território, Anghie argumenta que justificou-se, destarte, a chamada guerra justa sempre que houvesse resistência de povos nativos 
da América à invasão colonial espanhola, resistência esta que justificaria a tomada de incursões ilimitadas de guerra, da Espanha soberana, aos povos não soberanos da América. Nesse passo, aduz Anghie, ainda, que apresentadas sob um manto de neutralidade, as primeiras iniciativas doutrinárias em direito internacional, representadas sobretudo por Francisco de Vitoria, serviram, primordialmente, para assegurar o esmorecimento e o ostracismo dos povos conquistados.

Em um segundo momento, Anghie passa a dissertar sobre o colonialismo no século XIX, argumentando que o arcabouço doutrinário-legal da época, dominado pelo positivismo, concedeu, sob um manto de neutralidade, o ingresso no sistema do direito internacional a todas as nações soberanas — contudo, os requisitos de soberania partiam de premissas basicamente europeias, o que excluía, em grande parte, sociedades africanas e asiáticas. Nesse contexto, ainda que anteriormente recipientes de uma outorga falaciosa de soberania por partes dos poderes coloniais - cujo único objetivo era de dar ar de legalidade às espoliações coloniais previamente justificadas por meio de tratados internacionais eivados de vícios de consentimento - as nações africanas e asiáticas, em face de uma redefinição e consequente exclusão dos incivilizados do sistema de proteção internacional, foram deixadas à margem do direito. Dita teorização legal abriu caminho para que as potências europeias, reunidas durante a Conferência de Berlim de 1884-1885, pudessem conceituar em novos termos a noção de soberania, o que viria, sob o aspecto de uma missão civilizadora, a justificar a divisão e exploração colonial da África Subsaariana. O autor concluiu que o conceito de soberania, em razão de sua herança colonial, faz com que o seu exercício no plano internacional, ante a flexibilidade de ser um instrumento que possa ser utilizado para os fins da missão civilizadora — termo tão presente no século XIX — o qual, ainda atualmente, pode, sob o vocabulário de direitos humanos, governança e liberalização econômica, vir a reproduzir as desigualdades inerentes de sua redefinição.

Na terceira seção da obra, o autor foca sua atenção no Sistema de Mandato da Liga das Nações — em que a Liga das Nações, após o término da Primeira Guerra Mundial, por meio de um intrincado conjunto de elementos, levaria desenvolvimento a países outrora sob o domínio da Alemanha e do Império Otomano. Aponta que a análise acerca do referido sistema, substituído pelo sistema de tutela das Nações Unidas, descontinuado em
1994, e, atualmente, conforme a visão de Anghie, pelas instituições de Bretton Woods - o Banco Mundial e o Fundo Monetário Internacional —, traz à tona interessante conclusão: a possibilidade de análise, com precisão, das mudanças de paradigma na história do direito internacional — as quais foram abordadas em diversos trechos da obra do autor. Modificações do positivismo ao pragmatismo; do direito para as instituições; da soberania para o governo; de raça para a economia; da conquista para a descolonização; do colonialismo para o neocolonialismo; da exploração para o desenvolvimento; e da Inglaterra e França para os Estados Unidos podem ser analisadas e compreendidas no decorrer do livro de Anghie. Entretanto, no capítulo terceiro, o autor foca seus esforços na análise do conceito de soberania e sua relação de aparente igualdade para com todos os países, tanto europeus quanto não europeus. Anghie aduz que esse manto de legalidade aparente fundamenta o paradigma teórico do direito internacional atual, podendo ser traçado desde o século XIX com uma redefinição do conceito de soberania que ocultava um cerne de discriminação racial para uma conceptualização do termo, durante o período entre guerras, que viria abarcar, também, as desigualdades econômicas, o direito internacional atual serve, segundo Anghie, para uma expansão das hipóteses de intervenção - ocorre, historicamente, o desuso da palavra incivilizado, substituída pelo conceito de não-desenvolvido: ou seja, se verifica, no plano atual, a reprodução das premissas básicas da missão civilizadora e da dinâmica de diferença como fundamentadoras da própria estrutura, lógica e identidade das instituições internacionais. Cautelosamente, o autor indica que as constatações feitas não possuem um caráter acusatório, mas sim de melhoras dos sistemas internacionais atuais, para que se compreenda a operação e o papel que essas instituições possuem nas relações internacionais contemporâneas.

No quarto capítulo do livro, Anghie sustenta que, após o processo de descolonização e a criação de novos Estados, tanto acadêmicos ocidentais quanto não ocidentais reconheceram a necessidade de inclusão das reivindicações desses novos atores no ferramental do direito internacional. $\mathrm{Na}$ teoria, segundo o autor, esse não era um tema em disputa. Na prática, porém, os interesses dos países do Terceiro Mundo foram desconsiderados. Os novos Estados foram, assim, assimilados pelo mesmo direito internacional com bases e fundamentos eurocêntricos, tendo margem de negociação mínima na 
modificação e criação de novos tratados internacionais e acordos bilaterais. A eles restou o enquadramento às diretrizes pré-estabelecidas pelo direito internacional a fim de, também, pleitearem o ingresso no clube de países desenvolvidos. Anghie afirma que a distinção entre países desenvolvidos e em desenvolvimento se afigurou extremamente relevante para que as instituições de Bretton Woods justificassem sua operação. $\mathrm{O}$ autor reconhece, entretanto, que os países do Terceiro Mundo buscaram, com maior ou menor sucesso, conhecer e aplicar normas estabelecidas pelo direito internacional com o condão de obter vantagens no cenário internacional, principalmente na área de comércio e investimento.

Os conceitos de globalização, governança e seus impactos no cenário internacional, principalmente para as populações do Terceiro Mundo, são os pontos de análise do quinto capítulo. Ao citar Chimni, acadêmico que, assim como Anghie, adere às Abordagens de Terceiro Mundo do Direito Internacional (Third World Approaches to International Law - TWAIL), o autor expressa que, na era da globalização, o direito internacional representa o fantasma da recolonização. A atuação das instituições de Bretton Woods no design de diretrizes que impactam e vinculam investimentos, leis e políticas públicas no Terceiro Mundo constitui, na visão de Anghie, a longa manus de intenções neocolonialistas nos Estados do sul global. Em suma, o autor afirma que, enquanto o direito internacional protege a soberania dos países ocidentais, ao Terceiro Mundo esse direito é imposto, em detrimento de sua soberania.

Por fim, no sexto capítulo, Anghie questiona a utilização da ferramenta da intervenção humanitária como uma forma de subverter a soberania dos Estados do Terceiro Mundo. Partindo da análise da guerra contra o terror, expressão cunhada após o ataque terrorista de 11 de setembro de 2001, o autor critica a ideia de legítima defesa preventiva para justificar guerras no Terceiro Mundo (guerras por procuração). Ou seja, Anghie defende a tese de que se criou, após os atentados de 11 de setembro, uma permissão para a ingerência e o imperialismo nos países do Terceiro Mundo. Essa intromissão em assuntos internos estaria fundamentada no exercício da legítima defesa dos Estados ameaçados: ocorre que a aplicação do mecanismo de legítima defesa preventiva é bastante controversa, mesmo para o direito internacional mainstream.
Assim, partindo da premissa de que o direito internacional surge do encontro colonial, Anghie delineia, com base na análise do naturalismo jurídico do século $\mathrm{XVI}$, as ferramentas usadas pelo Ocidente para manter a dominância e a dependência dos países não ocidentais que marcaram o sistema colonial. Ao adquirir independência política, o Terceiro Mundo foi assimilado nas estruturas europeizadas já existentes do direito internacional, com reduzida margem de ingerência na negociação de acordos e tratados internacionais. A criação de Organizações Internacionais (ex: instituições de Bretton Woods), que promovem governança global, também seguiu a lógica de adequar Estados não desenvolvidos às práticas das potências do Primeiro Mundo, principalmente no que concerne ao comércio e investimento internacionais. A justificativa do tratamento assimétrico entre o Norte e o Sul sempre se fundamentou na ideia de dicotomia entre a essência dos ocidentais e não ocidentais, ou seja, entre civilizados e incivilizados. Ao final do livro, a perturbadora conclusão a que chega Anghie é a de que, apesar de se utilizar de ferramentas diversas, o imperialismo é uma constante na relação entre o mundo desenvolvido e a periferia global.

Em que pese a conclusão contundente a que Anghie chega, é interessante apontar que, apesar das imensas dificuldades que são percebidas pelos países do Terceiro Mundo nas relações internacionais e na lida com países cuja tradição jurídico-legal interna está incorporada ao ordenamento internacional, verifica-se que a curva de aprendizado de tais países está diminuindo substancialmente: por exemplo, o papel que o Brasil desempenhou na Organização Mundial do Comércio, no início dos anos 2000, denota que o país procurou internalizar e aplicar, de forma bastante eficiente, a visão multilateral do comércio internacional — ou seja, buscou, em conformidade com a moldura fornecida pelas instituições internacionais, avançar seus próprios interesses comerciais. Assim, ao mesmo tempo que as aproximações que o Brasil tem feito à Organização para a Cooperação e o Desenvolvimento Econômico, que também o colocam como aluno aplicado das normas de direito internacional impostas pelo Ocidente, o país se posiciona, ciente desse plano de fundo imperialista, dentro das regras do jogo, como um importante player regional e, caso consiga atuar sem reproduzir práticas neocolonialistas em suas relações comerciais com países menos desenvolvidos, pode exercer crescente referência positiva no cenário internacional. 
Para publicar na Revista de Direito Internacional, acesse o endereço eletrônico www.rdi.uniceub.br ou www.brazilianjournal.org.

Observe as normas de publicação, para facilitar e agilizar o trabalho de edição. 